is simple, clear, and expresses differences of a fundamental nature.

Each type is sub-divided into a number of "variations'. This term is unfortunate, for it has no genetical implication and is a purely formal expression of certain morphological concordances in embryonomy, grouping together plants which are otherwise unconnected. The term 'sub-type', though cumbrous, would have been better. Better still would have been the word 'pattern', which Johansen himself uses only in the Orchidaceæ, a family more or less sui generis embryologically. Terminology is, however, always a bone of contention between British and American authors and need not be further pursued here.

It is a reviewer's privilege to differ from his author ; but he must not be ungenerous to his merits. This work has been so carefully compiled and it is so fully documented that it gives a very favourable impression of accuracy and reliability. The book is really a most notable addition to botanical literature, and it will retain its place and value for a long time.

R. C. MCLEAN

\section{HANDBOOK OF ENSILAGE}

\section{Silage}

By Dr. Stephen J. Watson and Dr. A. M. Smith. (Agricultural and Horticultural Series.) Pp. $143+17$ plates. (London : Crosby Lockwood and Son, Ltd., 1951.) 10s. 6d. net.

$\mathrm{T}$ HE making of silage is no now thing in British farming. In the last quarter of the nineteenth century it had a considerable vogue, but the science of the process had not been worked out, mistakes were made and results were often disappointing; a few farmers persisted, but, speaking generally, silage. making languished for fifty years. During the Second World War great efforts were made to extend the practice, but these efforts had very little success. By this time much more was known of the changes which occur in green material when it is ensiled, but many farmers had not that knowledge and failed to appreciate that ensilage is merely a method of conservation and that it can never produce good feed from poor herbage. After the War farmers came to realize that the days of cheap imported feeding-stuffs were definitely ended, and not likely to return, and so they were ready to give ensilage a further trial and assign to it its proper important place in their farming systems.

Arable silage plays a part, but it is the ensiling of grass and clover which has been extended so much recently. Grassland provides by far the cheapest food for livestock, but the seasonality of its growth requires that the surplus of spring and early summer should be conserved for winter feeding The established method is haymaking; but this is dependent on the weather, and even in good conditions it entails considerable waste of nutrients. Artificial drying is increasing, but it is very expensive both for equipment and in operation. Ensiling grassland herbage costs less than half that of drying it artificially and, on the other hand, entails little more than half the nutrient loss that accompanies haymaking. It is the appreciation of these simple facts which has led to the remarkable increase in ensilage witnessed in the past two or three years, and it really does seem that the practice is now at last established in British farming.
There is no simple rule of thumb for making good silage. Details of the process must vary according to the material to be ensiled, the silo and equipment available, and to the weather at the time. For success, some knowledge of the principles involved is essential, and hitherto there has been no simple and complete handbook on the subject. Prof. S. J. Watson and Dr. A. M. Smith have met this need and met it very adequately. Their book is written in the plainest language ; it deals sufficiently with the underlying principles and exhaustively with the details of the various methods. The book will be welcomed by farmers and by students, and it should do much to consolidate the position which silage-making has newly won.

$$
\text { H. G. SANDERS }
$$

\section{STUDIES IN ECONOMETRICS}

Statistical Inference in Dynamic Economic Models By Cowles Commission Research Staff Members and Guests. Edited by Tjalling C. Koopmans. (Cowles Commission Monographs, No. 10.) Pp. $x v+438$. (New York: John Wiley and Sons, Inc.; London: Chapman and Hall, Ltd., 1950.) 48s. net.

rTHS book, to which eleven authors have contributed, represents the work which has been done by the members of the Cowles Commission and their collaborators during the past few years on the exploration of economic relationships by statistical methods. It is one of the most important works on econometrics which has yet appeared, and, although it is not easy to read, particularly for the economist with no special mathematical knowledge, it will be widely studied.

The basic problem of econometries is to set up a model of the economic system and to formulate the equations which determine its behaviour. This raises questions which are distinct in degree and emphasis, though not perhaps in kind, from the parallel problems of writing down the equations of physics. The approach of the Cowles Commission is to formulate a set of linear equations in two kinds of variables : endogenous, namely, those inherent in the economics of the system; and exogenous, namely, those which impinge on the system from without. The effect of disturbances and the impossibility of experimentation are taken into account by allowing these variables to incorporate a random element. There are then four classes of problem for examination: to set up the system of equations; to determine whether they are soluble; to construct a system of estimation for the unknown parameters; and to compare the results in practical cases to see whether they are plausible enough to justify acceptance of the model.

The basic memoir in this volume is that by Koop. mans, Rubin and Leipnik on "Measuring the Equation Systems of Dynamic Economics". The other articles develop various aspects of the subject in dealing with problems of identification, structural and predictive estimation and time-series. The papers, considered as a whole, are of a high standard ; but the connectivity of the treatment suffers from the fact that they are by different authors, there is no clear set of definitions of some of the terms employed, and no practical examples are given. This is therefore a book for the specialist. The Commission promises a further volume of a more expository character in which emphasis will be placed on basic ideas and techniques rather than on mathematical proofs. 